\title{
Evaluation of the surveillance system for undiagnosed serious infectious illness (USII) in intensive care units, England, 2011 to 2013
}

G Dabrera (zoonoses@phe.gov.uk)

1. UK Field Epidemiology Training Programme, Public Health England, London, United Kingdom

2. European Programme for Intervention Epidemiology Training (EPIET), European Centre for Disease Prevention and Control $(E C D C)$, Stockholm, Sweden

3. Centre for Infectious Disease Surveillance and Control, Public Health England, London, United Kingdom

4. Members of the group are listed at the end of the article

Dabrera G, Said B, Kirkbride H, On behalf of the USII Collaborating Group. Evaluation of the surveillance system for undiagnosed serious infectious illness (USII) in intensive care units, England, 2011 to 2013. Euro Surveill, 2014;19(46):pii=20961. Available online: http://www.eurosurveillance.org/ViewArticle. aspx?Articleld=20961

Article submitted on 10 November 2013 / published on 20 November 2014

Emerging infections are a potential risk during mass gathering events due to the congregation of large numbers of international travellers. To mitigate this risk for the London 2012 Olympic and Paralympic Games, a sentinel surveillance system was developed to identify clusters of emerging infections presenting as undiagnosed serious infectious illness (USII) in intensive care units (ICUs). Following a six month pilot period, which had begun in January 2011, the surveillance was operational for a further 18 months spanning the Games. The surveillance system and reported USII cases were reviewed and evaluated after this 18 month operational period including assessment of positive predictive value (PPV), timeliness, acceptability and sensitivity of the system. Surveillance records were used to review reported cases and calculate the PPV and median reporting times of USII surveillance. Sensitivity was assessed through comparison with the pilot period. Participating clinicians completed a five-point Likert scale questionnaire about the acceptability of surveillance. Between 11 July 2011 and 10 January 2013, 34 cases were reported. Of these, 22 remained classified as USII at the time of the evaluation, none of which were still hospitalised. No clusters were identified. The 22 USII cases had no association with the Games, suggesting that they represented the background level of USII in the area covered by the surveillance. This corresponded to an annualised rate of 0.39 cases $/ 100,000$ population and a PPV of $65 \%$. Clinicians involved in the surveillance reported high acceptability levels. The USII surveillance model could be a useful public health tool in other countries and during mass gathering events for identifying potential clusters of emerging infections.

\section{Introduction}

Mass gatherings have been described as 'a stress test for public health' by the Director General of World Health Organization (WHO) [1]; one of the challenges to public health is the potential for introduction of emerging infectious diseases due to the international movement of large numbers of people [2].

Emerging infections are a particular concern, as they can place a significant burden on public health and acute medical services within short time periods. A recent example is the Middle East respiratory syndrome coronavirus (MERS-CoV), which emerged in 2012 in the Arabian Peninsula [3]. The consecutive importation of MERS-CoV cases to the United Kingdom (UK) [4,5], Germany [6], France [7], Italy [8], Greece [9], the Netherlands [10], United States (US) [11] and Malaysia [12] required considerable public health resources with wide public health follow-up of contacts, extensive virological testing and international risk assessments.

Clinicians are accustomed to recognising and reporting specific diagnoses to public health surveillance systems. However, identification and reporting of emerging infections is problematic as these infections may not fit a recognisable clinical presentation and routine laboratory tests will not positively diagnose such cases. They are therefore less likely to be captured by traditional public health surveillance systems, instead requiring novel surveillance systems that aim to detect such cases of undiagnosed serious infectious illness (USII). The most severe emerging infections are likely to present to clinicians as USII in an acute medical setting such as intensive care units (ICUs). The ability to detect clusters of USII, related by common exposures, demographic or clinical characteristics could help to identify the first few cases of an emerging infection. This is especially important in complex health systems, where individual cases may be admitted to different hospitals.

To address these difficulties the Health Protection Agency (HPA, now part of Public Health England) 
developed a new surveillance system to detect cases and clusters of USII, as part of public health planning for the London 2012 Olympic and Paralympic Games between 27 July and 9 September [13,14]. The structure of this USII surveillance system is based on a sentinel network of ICUs and has been described in detail previously [15]. A sentinel structure was chosen to develop a proactive network of ICUs which reported regularly and provided good coverage in the areas of interest for a limited period related to the London 2012 Games. It was considered that this would have the potential to detect a proportion of any related cases of an emerging infection. These ICUs were chosen to provide good coverage in the areas of interest for a limited period related to the London 2012 Games. More comprehensive coverage would be necessary to develop an ongoing USII surveillance system for the whole country. The system was initially piloted in six ICUs for a period of six months starting from January 2011. It was then progressively expanded between July 2011 and February 2012, to a total of 19 units (including 12 adult units and 7 paediatric units), as part of the preparedness for the London 2012 Games [15]. All 19 units were enrolled by 27 February 2012. The surveillance system was operational for 18 months from 11 July 2011.

Immediately after the 18 months of operation and until March 2013, the USII surveillance system was reviewed and evaluated, using the Centers for Disease Control and Prevention (CDC) guidelines for the evaluation of surveillance systems [16]. The purpose of this report is to describe the cases reported to the system and to assess this surveillance system for future mass gatherings, in terms of its sensitivity, acceptability and simplicity to participating clinicians, positive predictive value (PPV), and timeliness of case reporting.

\section{Methods}

\section{Description of undiagnosed serious infectious}

illness surveillance

The USII surveillance system operated in 19 adult and paediatric ICUs (PICUs). These units were approached to participate on the basis of their proximity to games venues in the London region (13 units, of which eight were adult and five were paediatric units), or their role as major intensive care centres in the surrounding areas ( 4 in South East and 2 in East of England). These units participated on a voluntary basis and represented $48 \%$ and $59 \%$ of London ICU and PICU beds, respectively. The hospital represented by the units comprised a mix of large teaching hospitals and local acute hospitals, each with their own internal medical microbiology service and their own standard range of investigations. The majority of London 2012 Olympic and Paralympic Games activities were located in London and the South East regions. The USII case definition is shown in the Box. The USII diagnosis was made by clinicians in participating units on the basis of clinical opinion and hospital microbiology results; the precise microbiology tests used for cases varied

\section{Box}

Case definition, surveillance system for undiagnosed serious infectious illness, England, 2011-2013

Cases were defined as any child (aged $\leq 16$ years) or adult admitted to an intensive care unit with a serious illness suggestive of an infectious process, where the clinical presentation did not fit with any recognisable clinical picture or there was no improvement in response to standard therapy and initial laboratory investigations for infectious agents were negative or did not establish a diagnosis.

between units as each participating hospital had its own specialist microbiology service which operated independently. One or more lead clinicians from each participating ICU reported cases primarily through a dedicated online reporting tool but cases could also be notified by email or telephone. Information was collected on patient demographics, clinical presentation, travel history (including travel within the UK and abroad) and other relevant exposures. If no cases were identified, clinicians were asked to provide a nil report every two weeks (or weekly during the London 2012 Games period). Participating clinicians were able to update information for reported cases, such as new alternative diagnoses, via the web-based tool, email or telephone.

\section{Evaluation of undiagnosed serious infectious illness surveillance}

The evaluation involved a number of different approaches:

Retrospective analysis of cases and sensitivity of surveillance system

Data on cases reported during the 18 month period between 11 July 2011 and 10 January 2013, inclusive, were extracted from the secure web-based tool and added to a password-protected excel spreadsheet (Microsoft Excel 2007, Microsoft, Redmond, WA) which also contained data on cases reported by telephone and email. The cases which remained undiagnosed at the time of the evaluation (i.e. USII cases) were identified. The status of these cases was reviewed by the surveillance team in conjunction with the reporting clinicians, following the initial report and also during the evaluation, to ensure that they fulfilled the USII case definition. Cases were reviewed and described to provide an understanding of the role and function of the surveillance system.

The population coverage for the system was calculated as previously described [15] based on the proportion of all ICU beds in the local geographical area (as provided by each participating unit) and assuming a binomial distribution. This was used as the denominator, and the number of USII cases as the numerator, to calculate an annualised rate of USII assuming a Poisson distribution. 
Cases reported to the undiagnosed serious infectious illness surveillance system, England, 11 July 2011-10 January $2013(\mathrm{n}=34)$

\begin{tabular}{|c|c|c|}
\hline Characteristics of cases (total $=34$ ) & $\begin{array}{c}\text { USII cases } \\
\text { (total }=22 \text { ) } \\
n\end{array}$ & $\begin{array}{c}\text { Excluded } \\
\text { cases } \\
\text { (total }=12) \\
n\end{array}$ \\
\hline \multicolumn{3}{|l|}{ Age category (range: $4-69$ years) } \\
\hline Adult (>16 years-old) & 19 & 11 \\
\hline Child ( $\leq 16$ years-old) & 3 & 1 \\
\hline \multicolumn{3}{|l|}{ Sex } \\
\hline Male & 11 & 3 \\
\hline Female & 11 & 9 \\
\hline \multicolumn{3}{|l|}{ Predominant syndrome } \\
\hline Respiratory & 7 & 2 \\
\hline Presumed sepsis/bacteraemia & 5 & 5 \\
\hline Neurological & 4 & 2 \\
\hline Cardiac & 3 & o \\
\hline Haematologic & 1 & 0 \\
\hline Jaundice & 1 & 1 \\
\hline Metabolic & 1 & 1 \\
\hline Not stated & 0 & 1 \\
\hline \multicolumn{3}{|l|}{ Possible travel exposures } \\
\hline $\begin{array}{l}\text { Travelled outside UK in the } \\
\text { preceding six months }\end{array}$ & 10 & 2 \\
\hline \multicolumn{3}{|l|}{ Outcome } \\
\hline Death & 10 & 5 \\
\hline $\begin{array}{l}\text { Discharge from intensive } \\
\text { care unit }\end{array}$ & 10 & 4 \\
\hline Unknown & 2 & 3 \\
\hline
\end{tabular}

UK: United Kingdom; USII: undiagnosed serious infectious illness.

A 95\% Bonferroni-type confidence interval (Cl) was calculated to reflect the variability in the population covered over time. This was produced by calculating $\mathrm{Cls}$ using the lower and upper limits of the annualised rate of USII; the lowest of the lower limits and the highest of the upper limits, formed the lower and upper limits of the $95 \%$ Bonferroni-type $\mathrm{Cl}$, respectively.

These annualised rates were calculated overall for all ages and separately for adult and for paediatric (aged less than or equal to 16 years) cases and compared to the published rate from the pilot period [15], to assess the sensitivity of the surveillance system.

\section{Acceptability and simplicity}

This was assessed during site visits and meetings with clinicians at each participating trust by the authors (GD, BS, HK). Clinicians were asked to complete a short paper-based questionnaire using a five point Likert scale during these visits. The questionnaire asked about their understanding of the role of the USII surveillance system, the acceptability of sending a fortnightly nil report and their willingness to continue reporting USII cases in the future. To assess simplicity, participants were specifically asked how easy the case definition and the web-tool were to use. Completed paper questionnaires were double-entered using Epidata Entry v3.1 (The Epidata Association, Odense Denmark, 2008) and exported to Microsoft Excel 2007 (Microsoft, Redmond, WA) for analysis. The responses to each point of the Likert scale were summarised as counts in relation to the total number of completed questionnaires.

Positive predictive value

USII is a clinical diagnosis and there is no 'gold standard' test for this, with the diagnosis made by clinicians. Consequently cases initially reported as USII may cease to be considered cases if they receive an alternative diagnosis at a later stage. The PPV is therefore calculated as:

- Number of cases with USII as a final diagnosis/ (Number of cases with USII as a final diagnosis + Number of cases initially reported USII but later received alternative diagnosis) $\times 100$

This was defined as the proportion of all cases reported to the surveillance system, which remained USII (i.e. which were not subsequently diagnosed) at the time of last report. Counts of cases notified to the USII surveillance system and of those which were subsequently diagnosed at the date of last report or outcome notification, were identified from the previously described password-protected excel spreadsheet holding case data.

\section{Timeliness}

The reporting time was defined as the number of days elapsed between a case being admitted to a participating unit and reported to the USII surveillance system. The following data fields were extracted from the online reporting tool for each case: date of admission and date of reporting for cases notified using the reporting tool between 11 July 2011 and 10 January 2013 , inclusive. The median and range of reporting times was calculated for these cases. Timeliness was similarly calculated for those cases reported by email or telephone which had a recorded date of admission in surveillance records.

\section{Results}

Retrospective analysis of cases and sensitivity of the surveillance system

During the evaluation period, 34 cases were reported to USII surveillance by participating units (Table 1). Of these, 27 were notified online, six by email and one by telephone. A total of 12 cases were subsequently diagnosed and were no longer classified as USII cases, leaving 22 cases that remained USII (20 reported online and two by email) (Table 1 and 2). 
At the time of the evaluation, none of the 22 cases that remained USII were hospitalised, as 12 had been discharged and the remainder had died. Of the 22 USII cases, 11 were male and 11 were female with ages rang. ing between four and 69 years. The principal presenting syndrome was respiratory illness (seven cases), followed by presumed sepsis/bacteraemia (five cases), neurological (four cases) and cardiac (three cases). Nineteen cases were adults and three were paediatric cases (less than 16 years-old). Ten of the adult cases had a history of travel outside the UK in the preceding six months. None of the paediatric cases had a travel history. There were no relevant exposures identified for four cases and no exposure information was given for the remaining five cases. Ten of the USII cases were fatal, giving a case fatality rate of $10 / 22(45 \%)$.

There was no clustering of USII cases by clinical presentation, exposure or demographic characteristics identified during the evaluation period, including the period of the London 2012 Olympic and Paralympic Games (Figure). The 22 USIl cases detected had no association with the Olympic or Paralympic Games.

Of the subsequently denotified cases most were female (9 cases), the age range was 11 to 77 years, and the main presenting syndrome was presumed sepsis/ bacteraemia ( 5 cases). The infectious diagnoses for 10 cases or reasons for exclusion (one immunocompromised and one non-infectious and therefore outside the case definition) of these cases are shown in Table
2. The median time from ICU admission to denotification was 10 days (range: 8-41 days).

The annualised rate of all-age USII cases was 0.39 cases per 100,000 persons ( $95 \% \mathrm{Cl}: 0.23-0.64$ ). The annualised rate for adult USII cases was 0.61 cases per 100,000 persons ( $95 \% \mathrm{Cl}: 0.34-1.1$ ), while the annualised rate for paediatric cases was 0.067 per 100,000 persons ( $95 \% \mathrm{Cl}$ : 0.012-0.22).

The USII rate reported in this study was lower than that found during the initial USII pilot (an estimated annual rate of 1.2 per 100,000 persons, with a range of $0.4^{-}$ 3.1 per $100,000[15])$.

\section{Acceptability and simplicity}

Twenty-two participating clinicians completed questionnaires during site visits by the surveillance team. The majority $(n=20)$ of respondents either agreed $(n=8)$ or strongly agreed $(n=12)$ that they understood the role of the USII surveillance system in identifying unknown infective syndromes. In addition 17 respondents agreed $(n=10)$ or strongly agreed $(n=7)$ that the request for a nil report every two weeks was convenient. Furthermore, 19 respondents stated that they would be prepared to continue reporting to the USII system.

Most respondents either strongly agreed $(n=8)$ or agreed $(n=11)$ with the statements that the USII case definition was easy to use and apply to cases. Approximately half of the respondents reported that

\section{FIGURE}

Distribution of undiagnosed serious infectious illness cases, England, 11 July 2011-10 January 2013 (n=22)

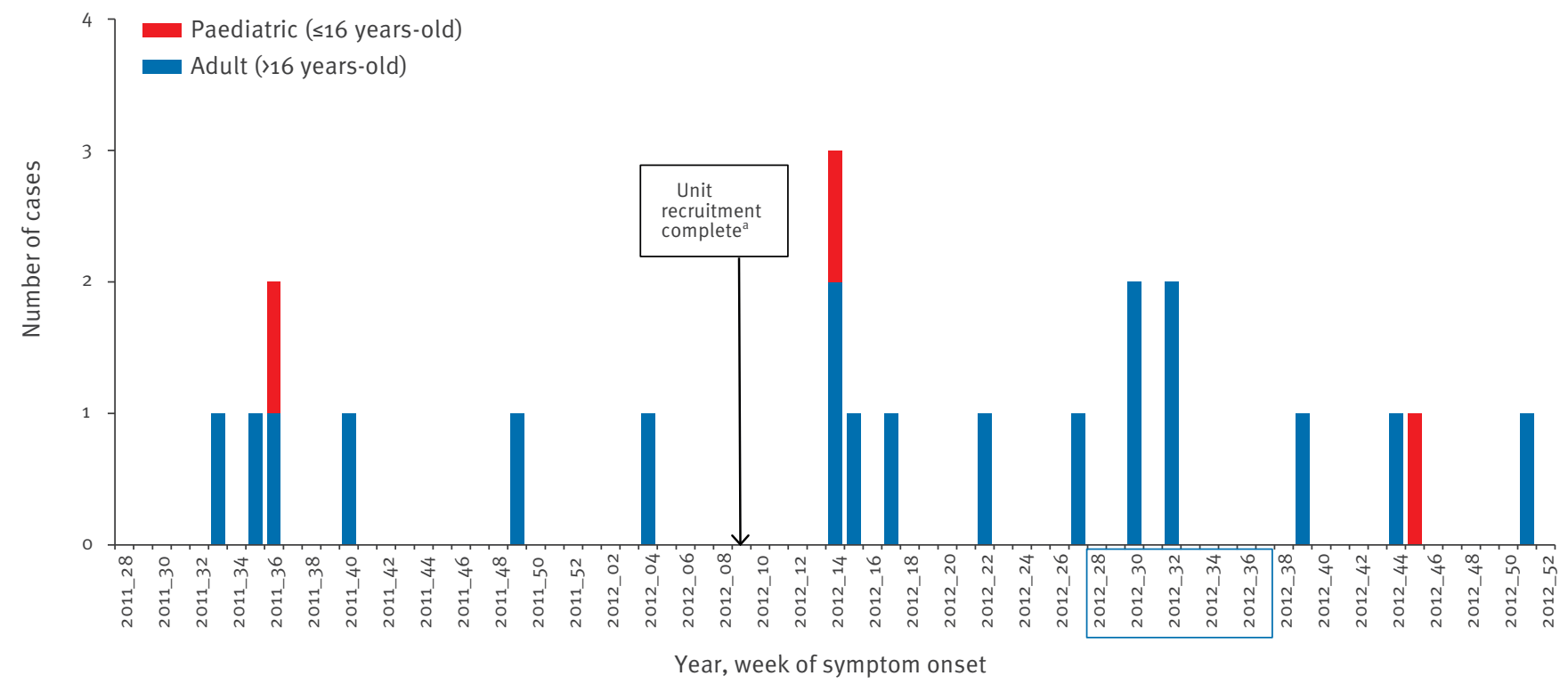

Week 32 in 2011 starts on 8 August. On the X axis label, the period corresponding to the Olympic and Paralympic Games is surrounded by a square box.

Starting from January 2011 , in a period lasting six months, which does not figure on the graph, a pilot sentinel surveillance of undiagnosed serious infectious illness cases, including six intensive care units (ICUs) was developed. From July 2011 , the number of ICUs in the surveillance was expanded, reaching 19 units in February 2012. 


\section{TABLE 2}

Initial cases reported to the surveillance system for undiagnosed serious infectious illness, that were subsequently denotified due to a diagnosis, England, 11 July 2011-10 January $2013(\mathrm{n}=12)$

\begin{tabular}{|c|c|c|}
\hline \multirow{2}{*}{$\begin{array}{l}\text { Final } \\
\text { diagnoses } \\
\text { of initial } \\
\text { USIl cases } \\
\text { which were } \\
\text { denotified } \\
(n=12)\end{array}$} & $\begin{array}{l}\text { Infectious } \\
\text { disease } \\
(n=10)\end{array}$ & $\begin{array}{l}\text { Histoplasmosis } \\
\text { Invasive aspergillosis } \\
\text { Leptospirosis } \\
\text { Pseudomonas bacteraemia } \\
\text { Pneumococcal sepsis } \\
\text { Disseminated tuberculosis } \\
\text { Amp C beta-lactamase producing } \\
\text { E. coli bacteraemia } \\
\text { Staphylococcus bacteraemia } \\
\text { Haemophilus spp. respiratory } \\
\text { infection } \\
\text { Enterococcus bacteraemia }\end{array}$ \\
\hline & $\begin{array}{l}\text { Non-infectious } \\
\text { disease/ } \\
\text { condition } \\
(n=2)\end{array}$ & $\begin{array}{l}\text { Immunocompromised } \\
\text { Antibody-mediated encephalitis }\end{array}$ \\
\hline
\end{tabular}

E. coli: Escherichia coli; USII: undiagnosed serious infectious illness.

the reporting tool was easy to use (4 strongly agreed and 8 agreed).

\section{Positive predictive value}

Of the 34 cases reported to the USII surveillance system, 22 remained USII. The positive predictive value for a case reported to the surveillance system remaining a USII case was $65 \%$.

\section{Timeliness}

Data were available to calculate median reporting time for 27 cases reported via the online reporting tool. The median reporting time for USII cases was 11 days following admission to ICU (range: 3-52 days). The median reporting time for three cases reported by email/telephone was 16 days (range: 2-49 days).

\section{Discussion}

The USII system is a unique surveillance system developed as part of a range of new and enhanced surveillance systems for the London 2012 Games. To our knowledge, there have been only two similar surveillance systems $[17,18]$ described previously in the literature although these were not specifically developed for mass gatherings.

During 18 months of full operation a total of 22 cases of USII were identified through 19 participating ICUs. This is equivalent to a rate of 0.39 cases per 100,000 persons ( $95 \% \mathrm{Cl}: 0.23-0.64)$ and along with the absence of any clusters, indicates that as expected, USII cases are rare. However, these cases were associated with a case fatality of $45 \%$ which was considered to be high by many of the participating clinicians. None of the cases were associated with the London 2012 Games suggesting that observed cases represent the background level of USII in the area covered by the surveillance.

One of the difficulties in undertaking surveillance for USII is that the diagnosis is based on exclusion of known infections, and therefore depends on the extent of laboratory investigation. This may vary between different clinicians depending on local protocols and clinical experience. It is, in addition, difficult to distinguish between an unknown serious infectious illness and an unknown serious illness (which may not be infectious).

The lower USII rate reported in this study compared to a previous USII pilot was accompanied by an increase in the PPV between the evaluation (65\%) and pilot periods (50\%). We hypothesise that the pilot provided a period of initial learning, where clinicians were becoming accustomed to the case definition. Subsequently, the experience from the pilot period may have led to a higher threshold for reporting cases and therefore lower USII rates, during the evaluation period.

The results of the evaluation show that the USII system was acceptable to clinicians and that the system was simple to use both in terms of applying the case definition and reporting via the web-based tool. The simplicity of a reporting procedure has previously been reported as a key factor for increasing participants' willingness to report cases of infectious diseases [19]. These factors, in combination with the rarity of cases, may explain the willingness of clinicians to continue reporting.

The USII surveillance was an integral part of the surveillance initiatives introduced during the 2012 Olympics and Paralympics to monitor the potential threat of emerging infections. For instance, the HPA and European Centre for Disease Prevention and Control (ECDC) worked jointly to identify and risk assess infectious disease hazards occurring outside the UK which may have had an impact on the Olympic and Paralympic Games $[14,20]$. In addition, syndromic surveillance was expanded to detect signals of uncommon illnesses $[13,21]$. However, the USII system was unique in having the capability to collect case-level information on potential cases of new and emerging infections.

The length of the reporting times identified by this evaluation can be explained by the need to investigate suspected cases following admission, before considering a USII diagnosis. It is difficult to make an informed decision about whether these reporting times are adequate or too short, in relation to characteristics such as incubation period, as these are by definition, unknown for USII. However, this does reinforce the advantages for timeliness of using electronic reporting systems as demonstrated by other authors [22].

Data from similar surveillance have only been published from systems in Taiwan (2000-2005) and the 
US (1995-1998). These show similar proportions in the presentations of reported cases. As in this study, where the majority (7/22) of USII cases had respiratory illness, surveillance from Taiwan also found that respiratory syndromes were most common, accounting for $59 \%$ of cases [17]. Respiratory syndromes were also the second most common presentation for the US system, accounting for $26 \%$ of cases, although this was closely preceded by neurological presentations (29\%) [18]. The latter were less common among our cases. The USII surveillance approach may therefore be useful in addressing new and emerging respiratory infections such as influenza $\mathrm{A}\left(\mathrm{H}_{7} \mathrm{~N} 9\right)$ in China [23,24].

One of the strengths of this evaluation is that we checked reported cases for diagnoses up to the end of the evaluation, maximising the length of follow-up of these cases. This allowed the exclusion of those cases which were diagnosed at later stage, which may be due to results from specialist testing, therefore retaining true USII cases only and making USII case rates more accurate.

As the study was undertaken in an acute health system in England, we anticipate that countries with similar health systems may also benefit from implementing USII surveillance during other mass gatherings. However, the challenge of emerging infections is not limited to just mass gatherings but is a persistent issue occurring in many settings, as evidenced by MERS-CoV [25] and influenza $A\left(\mathrm{H}_{7} \mathrm{~N} 9\right)$ in China $[23,24]$. We argue that USII surveillance may be useful for such rapidly evolving situations where the capability to detect emerging infections is required. This surveillance is practical to operate, requiring only half a full-time epidemiological scientist and support from a consultant epidemiologist.

The official report into public health activities during the London 2012 Games highlighted the importance of surveillance systems such as USII to public health services during mass gatherings and advocated maintaining the USII system or being able to reactivate it in the future [26]. More general, population-wide surveillance would require a remodelling of the system and its processes in terms of increasing the number and distribution of participating ICUs, to ensure sufficient coverage across England and to improve sustainability. We will investigate the feasibility of developing USII beyond its original mass gathering function, in order to address the general, ongoing threat from emerging infections.

\section{Conclusion}

Emerging infections pose a constant challenge globally and the USII surveillance model could also be a useful public health tool in other countries, seeking to identify clusters of USII. Prospective surveillance within the ICU setting is simple and acceptable to clinicians and provides a valuable opportunity for the identification of clusters of emerging infections.
The USII Collaborators

(1) The USII Steering Group: commissioned the evaluation of the system, reviewed and commented on the manuscript. In addition to the named authors the USII Steering Group consisted of: Barbara Bannister, David Brown, Deborah Turbitt, Dilys Morgan, Ed Kaczmarski, Ellen Heinsbroek, Gillian Smith, Mandy Walsh, Meera Chand, Rohini Manuel, Saheer Gharbia and Tim Dallman.

(2) ICU Clinicians (participated in the surveillance and contributed to the evaluation): Dr Richard Leonard (AICU team, St. Mary's Hospital); Dr Simon Nadel (PICU team, St. Mary's Hospital); Dr Jonathan Ball (ICU team, St George's Hospital, London); Dr Martin Gray, Dr Linda Murdoch, Nargis Hemat (PICU team, St Georges Hospital, London); Dr Robert Ghosh, Shaun Mcauliffe, Tom Honisett, Dr Alleyna Claxton (ICU team, The Homerton Hospital); Dr Shane Tibby (PICU team, Evelina Children's Hospital); Dr Andrew Carmichael (Addenbrooke's Hospital Cambridge); Dr Nan Shetty (Clinical Microbiologist, UCLH); Dr David Pogson, Dr Bruce Taylor, Steven Rose (Associate Academic Department of Critical Care, University of Portsmouth \& Portsmouth Hospitals); Dr Andre Vercueil, Dr Tom Hurst (ICU team, Kings College Hospital); Dr Akash Deep (PICU team, Kings College Hospital); Dr Paula Lister, Amy Jones (PICU team, Great Ormond Street Hospital); Dr Rebecca Cusack, Dr Mike Celinski (ICU team, University Hospital Southampton); Dr lain Maclntosh (PICU team, University Hospital Southampton); Dr David Land (HDU team, University Hospital Southampton); Dr James Napier, Dr Peter Wilson (Newham Hospital); Dr Gerlinde Mandersloot, Dr Marie Healy (ICU team, Royal London Hospital); Dr Ruth Griffin (ICU team, Hillingdon Hospital).

\section{Acknowledgements}

We would like to thank all the healthcare staff at participating trusts who supported ICU clinicians in undertaking this surveillance, without which this work would not have been possible. Thanks to Dr Sam Bracebridge, FETP Director, Dr Richard Pebody, FETP supervisor, Neville Verlander, statistician. This work was presented at ESCAIDE 2013.

\section{Conflict of interest}

GD, BS, HK employed by Public Health England which operates the USII system.

\section{Authors' contributions}

GD: Undertook the evaluation, wrote manuscript; BS: Contributed to the evaluation, wrote manuscript, manages USII surveillance system; HK: Contributed to the evaluation, wrote manuscript, leads USII surveillance system.

\section{References}

1. World Health Organization (WHO). Communicable disease alert and response for mass gatherings. Geneva: WHO. [Accessed 1 Aug 2013]. Available from: http://www.who.int/csr/ mass_gatherings/en/

2. Abubakar I, Gautret P, Brunette GW, Blumberg L, Johnson D, Poumerol G, et al. Global perspectives for prevention of infectious diseases associated with mass gatherings. Lancet Infect Dis. 2012;12(1):66-74. http://dx.doi.org/10.1016/S14733099(11)70246-8 PMID:22192131

3. Danielsson N, Catchpole M; ECDC Internal Response Team. Novel coronavirus associated with severe respiratory disease: case definition and public health measures. Euro Surveill. 2012;17(39): pii=20282. PMID:23041021

4. Pebody RG, Chand MA, Thomas HL, Green HK, Boddington NL, Carvalho C, et al. The United Kingdom public health response to an imported laboratory confirmed case of 
a novel coronavirus in September 2012. Euro Surveill. 2012;17(40): $\mathrm{pii}=20292$. PMID:23078799

5. Health Protection Agency (HPA) UK Novel Coronavirus Investigation team. Evidence of person-to-person transmission within a family cluster of novel coronavirus infections, United Kingdom, February 2013. Euro Surveill. 2013;18(11): pii=20427. PMID:23517868

6. Buchholz U, Müller MA, Nitsche A, Sanewski A, Wevering N, Bauer-Balci T, et al. Contact investigation of a case of human novel coronavirus infection treated in a German hospital, October-November 2012. Euro Surveill. 2013;18(8):pii=20406. PMID:23449231

7. Mailles A, Blanckaert K, Chaud P, van der Werf S, Lina B, Caro V, et al.; investigation team. First cases of Middle East Respiratory Syndrome Coronavirus (MERS-CoV) infections in France, investigations and implications for the prevention of human-to-human transmission, France, May 2013. Euro Surveill. 2013;18(24):pii=20502. PMID:23787161

8. Puzelli S, Azzi A, Santini MG, Di Martino A, Facchini M, Castrucci MR, et al. Investigation of an imported case of Middle East Respiratory Syndrome Coronavirus (MERS-CoV) infection in Florence, Italy, May to June 2013. Euro Surveill. 2013;18(34): pii=20564. http://dx.doi.org/10.2807/1560-7917. ES2013.18.34.20564 PMID:23987829

9. Tsiodras S, Baka A, Mentis A, Iliopoulos D, Dedoukou X, Papamavrou G, et al. A case of imported Middle East Respiratory Syndrome coronavirus infection and public health response, Greece, April 2014. Euro Surveill.

2014;19(16):pii=20782. http://dx.doi.org/10.2807/1560-7917. ES2014.19.16.20782 PMID:24786258

10. Kraaij-Dirkzwager M, Timen A, Dirksen K, Gelinck L, Leyten E, Groeneveld P, et al.; MERS-CoV outbreak investigation team of the Netherlands. Middle East respiratory syndrome coronavirus (MERS-CoV) infections in two returning travellers in the Netherlands, May 2014. Euro Surveill. 2014;19(21): pii=20817. http://dx.doi.org/10.2807/1560-7917.ES2014.19.21.20817 PMID:24906375

11. Bialek SR, Allen D, Alvarado-Ramy F, Arthur R, Balajee A, Bell $D$, et al.; Centers for Disease Control and Prevention (CDC). First confirmed cases of Middle East respiratory syndrome coronavirus (MERS-CoV) infection in the United States, updated information on the epidemiology of MERS-CoV infection, and guidance for the public, clinicians, and public health authorities - May 2014. MMWR Morb Mortal Wkly Rep. 2014;63(19):431-6. PMID:24827411

12. Premila Devi J, Noraini W, Norhayati R, Chee Kheong C, Badrul AS, Zainah S, et al. Laboratory-confirmed case of Middle East respiratory syndrome coronavirus (MERS-CoV) infection in Malaysia: preparedness and response, April 2014. Euro Surveill. 2014:19(18): $\mathrm{pii}=20797$. http://dx.doi. org/10.2807/1560-7917.ES2014.19.18.20797 PMID:24832116

13. Severi E, Heinsbroek E, Watson C, Catchpole M; HPA Olympics Surveillance Work Group. Infectious disease surveillance for the London 2012 Olympic and Paralympic Games. Euro Surveill. 2012;17(31): pii=20232. PMID:22874458

14. Jones J, Lawrence J, Payne Hallström L, Mantero J, Kirkbride $\mathrm{H}$, Walsh A, et al.; international team. International infectious disease surveillance during the London Olympic and Paralympic Games 2012: process and outcomes. Euro Surveill. 2013;18(32): $\mathrm{pii}=20554$. http://dx.doi.org/10.2807/1560-7917. ES2013.18.32.20554 PMID:23968829

15. Heinsbroek E, Said B, Kirkbride H; HPA USII Steering Group. A new surveillance system for undiagnosed serious infectious illness for the London 2012 Olympic and Paralympic Games. Euro Surveill. 2012;17(31):pii= 20237. PMID:22874459

16. German RR, Lee LM, Horan JM, Milstein RL, Pertowski CA, Waller MN, et al. Updated guidelines for evaluating public health surveillance systems: recommendations from the Guidelines Working Group. MMWR Recomm Reports. 2001;50(RR-13):1-35. PMID: 18634202

17. Wang T-H, Wei K-C, Jiang DD, Chiu C-H, Chang S-C, Wang -D. Unexplained deaths and critical illnesses of suspected infectious cause, Taiwan, 2000-2005. Emerg Infect Dis. 2008;14(10):1653-5. http://dx.doi.org/10.3201/eid1410.061587 PMID:18826839

18. Hajjeh RA, Relman D, Cieslak PR, Sofair AN, Passaro D, Flood J, et al. Surveillance for unexplained deaths and critical illnesses due to possibly infectious causes, United States, 1995-1998. Emerg Infect Dis. 2002;8(2):145-53. http://dx.doi.org/10.3201/ eido802.010165 PMID:11897065

19. Tan H-F, Yeh C-Y, Chang H-W, Chang C-K, Tseng H-F. Private doctors' practices, knowledge, and attitude to reporting of communicable diseases: a national survey in Taiwan. BMC Infect Dis. 2009;9(1):11. http://dx.doi.org/10.1186/1471-23349-11 PMID:19178741
20. Economopoulou A, Kinross P, Domanovic D, Coulombier D. Infectious diseases prioritisation for event-based surveillance at the European Union level for the 2012 Olympic and Paralympic Games. Euro Surveill. 2014;19(15):pii=20770. http://dx.doi.org/10.2807/1560-7917.ES2014.19.15.20770 PMID:24762663

21. Morbey RA, Elliot AJ, Charlett A, Ibbotson S, Verlander NQ, Leach S, et al. Using public health scenarios to predict the utility of a national syndromic surveillance programme during the 2012 London Olympic and Paralympic Games. Epidemiol Infect. 2014;142(5):984-93. http://dx.doi.org/10.1017/ So95026881300188X PMID:23902949

22. Jansson A, Arneborn M, Skärlund K, Ekdahl K. Timeliness of case reporting in the Swedish statutory surveillance of communicable diseases 1998--2002. Scand J Infect Dis. 2004;36(11-12):865-72. http://dx.doi. org/10.1080/00365540410025348 PMID:15764175

23. Lo YC, Chen WC, Huang WT, Lin YC, Liu MC, Kuo HW, et al. Surveillance of avian influenza $\mathrm{A}\left(\mathrm{H}_{7} \mathrm{Ng}\right)$ virus infection in humans and detection of the first imported human case in Taiwan, 3 April to 10 May 2013. Euro Surveill. 2013;18(20):pii= 20479. PMID:23725865

24. Ai J, Huang Y, Xu K, Ren D, Qi X, Ji H, et al. Case-control study of risk factors for human infection with influenza $\mathrm{A}\left(\mathrm{H}_{7} \mathrm{~N} 9\right)$ virus in Jiangsu Province, China, 2013. Euro Surveill. 2013;18(26): pii=20510. http://dx.doi.org/10.2807/1560-7917. ES2013.18.26.20510 PMID:23827526

25. Penttinen PM, Kaasik-Aaslav K, Friaux A, Donachie A, Sudre $B$, Amato-Gauci AJ, et al. Taking stock of the first 133 MERS coronavirus cases globally--Is the epidemic changing? Euro Surveill. 2013;18(39):pii=20596. http://dx.doi. org/10.2807/1560-7917.ES2013.18.39.20596 PMID:24094061

26. Endericks T, McCloskey B. London 2012 Olympic and Paralympic Games Summary Report of the Health Protection Agency's Games Time Activities;. 2013 Jan. p. 44 Available from: http://www.hpa.org.uk/webc/HPAwebFile/ HPAweb_C/1317137705751</eref> 